\title{
STUDY ON SPECIES OF HEAVY LANTHANIDES(III) CHELATES EXTRACTED INTO ORGANIC PHASE WITH 5,7-DICHLORO-8-HYDROXYQUINOLINE
}

\author{
D. Czakis-Sulikowska, A. Malinowska, N. Pustelnik and B. Kuźnik \\ Insitute of General and Ecological Chemistry, Technical University of Łódź \\ Żwirki 36, 90-924 Lódź, Poland
}

The nature of species formed in the extraction of lanthanides Ln(III) (where $\mathrm{Ln}=\mathrm{Tb}, \mathrm{Dy}, \mathrm{Ho}, \mathrm{Er}, \mathrm{Tm}$ and $\mathrm{Yb}$ ) with 5,7-dichloro-8-hydro xyquinoline (IL) in $\mathrm{CHCl}_{3}$ from water or water-methanol phase was examined. It was stated that during the extraction from water phase the chelates $\mathrm{LnL}_{3}\left(\mathrm{~Tb}, \mathrm{Tm}\right.$ ), seven-coordinated self-adducts $\mathrm{LnL}_{3} \div \mathrm{HL}$ (Er, Ho) or both types of these species (Dy, Yb) were extracted. In the presence of methanol (MeOHI) in the aqueous phase the eight-coordinated mixed species of the type $\mathrm{LnL}_{3} \cdot 2 \mathrm{MeOH}$ were observed.

PACS numbers: $81.10 . \mathrm{Dn}, 82.30 . \mathrm{II}$

\section{Introduction}

The study of the nature of species formed in the extraction of lanthanide ions have been the subject of extensive investigations during the last few years [1,2]. Ilowever, there is scanty information on the species of the lanthanide chelates extracted into organic phase with different $\mathrm{N}, \mathrm{O}$ or $\mathrm{O}, \mathrm{O}$ donor extractants [3-5]. 8-Hydroxyquinoline (IIOx) and its derivatives are one of the most important and interesting of these extractants, since they form not only simple chelates but also self-adducts and mixed ligand adducts in the presence of other neutral ligands $[4,6,7]$.

Now, particular attention is given to the extraction of heavy lanthanides with 5,7-dichloro-8-hydroxyquinoline (IIL or $5,7(\mathrm{Cl}) \mathrm{HO}$ ) which may be preferable to 8-hydroxyquinoline as a reagent for solvent extraction [6]. The nature of species extracted into organic phase in the systems $\mathrm{Ln}(\mathrm{III})-\mathrm{H}_{2} \mathrm{O}-\mathrm{IIL}-\mathrm{CHCl}_{3}$ and $\mathrm{Ln}(\mathrm{III})-\mathrm{II}_{2} \mathrm{O}-\mathrm{MeOII}-\mathrm{IIL}-\mathrm{CIICl}_{3}$ (where $\mathrm{Ln}(\mathrm{III})=\mathrm{Tb}, \mathrm{Dy}$, Ho, Er, Tm, Yb; MeOH - methanol) was investigated. 


\section{Experimental}

The solutions of $\mathrm{Ln}\left(\mathrm{ClO}_{4}\right)_{3}(\mathrm{Ln}(\mathrm{III})=\mathrm{Tb}$, $\mathrm{Dy}$, IIo, Er, Tm and $\mathrm{Yb}$ ) were prepared from the corresponding $\mathrm{Ln}_{2} \mathrm{O}_{3}$ (99.9\% Fluka). 5,7-Dichloro-8-hydroxyquinoline (99.9\% Aldrich Chemical) solutions in chloroform were used. The experimental procedure, apparatus and other reagents used have been described previously [5].

Studies on the extraction of lantahnides(III) from water phase were carried out at varying $C_{\mathrm{IL}(\mathrm{o})}\left(1.5 \times 10^{-3} \div 3.00 \times 10^{-2} \mathrm{~mol} / \mathrm{l},(\mathrm{o})\right.$ - denotes the organic phase) and pII $\approx 4 \div 5.5$. Two series of experiments:

- at varying $C_{\mathrm{IL}(0)}\left(1.5 \times 10^{-3} \div 3.00 \times 10^{-2} \mathrm{~mol} / \mathrm{l}\right)$ and $C_{\mathrm{MeOH}}=50 \%(\mathrm{~V} / \mathrm{V})$,

- at varying $C_{\mathrm{MeOI}}(5 \div 50 \%(\mathrm{~V} / \mathrm{V}))$ and $C_{\mathrm{IL}(\mathrm{o})}=3.00 \times 10^{-2} \mathrm{~mol} / \mathrm{l}$, during the extraction from water-methanol phase $\left(\mathrm{pII}^{*} \approx 3.5 \div 5\right.$ where $\mathrm{pII}^{*}=$ $-\log \left[\mathrm{II}^{+}\right]$in water-methanol solutions [8]) were performed. In all series of measurements the concentration of $\operatorname{Ln}(\mathrm{III})$ was $50 \mu \mathrm{g} / \mathrm{ml}$. Experiments were carried out at $21 \pm 1^{\circ} \mathrm{C}$ and at constant ionic strength $(\mu=0.1 \mathrm{~mol} / \mathrm{l})$.

\section{Results and discussion}

The overall reaction for the extraction of investigated ions with 5,7-dichloro-8-hydroxyquinoline can be represented by equation

$$
\begin{aligned}
\mathrm{Ln}\left(\mathrm{II}_{2} \mathrm{O}\right)_{y}^{3+}+ & (3+n) \mathrm{IIL}_{(\mathrm{o})}+\mathrm{tMeOII}_{(\mathrm{o})} \leftrightarrow \mathrm{LnL}_{3} \cdot n \mathrm{HL} \cdot \mathrm{tMeOII}_{(\mathrm{o})} \\
+ & 3 \mathrm{II}^{+}+y \mathrm{II}_{2} \mathrm{O} .
\end{aligned}
$$

As can be seen from Eq. (1) the extraction behaviour of the lanthanides may be evaluated from a log-log plot of the distribution coefficient $(D)$ vs. equilibrium concentration of IIL or MeOII in the organic plase. Taking into account the hydrogen ion concentration, volume changes of phases, the IIL and $\mathrm{II}_{2} \mathrm{~L}^{+}$acid dissociation constants and the IIL distribution constants, the equilibrium concentration ([IIL $(\circ)]$ ) was calculated $[9,10]$. Equilibrium concentration of methanol in organic phase $\left(\left[\mathrm{MeOII}_{(0)}\right]\right)$ in relation to its initial concentrations in water-methanol solutions, were determined chromatographically [11].

Examples of the results of investigations are shown in Figs. 1 and 2 whereas data concerning the species extracted into organic phase are compiled in Table. Plots of $\log -3$ pII vs. $\log \left[\Pi \mathrm{IL}_{(\mathrm{o})}\right]$ (for the extraction from water phase) indicated linear relationships with slopes $\approx 3(\mathrm{~Tb}, \mathrm{Tm})$ and $\approx 4$ (IIo, Er). In contrast, slopes intermediate between 3 and 4 for Dy and Y $\mathrm{rb}$ were observed. Finally, it was stated that during the extraction from water phase the chelates $\mathrm{LnL}_{3}$, seven-coordinated self-adducts $\mathrm{LnL}_{3}$. IIL or both types of these species are formed. Previously [5], it was shown that in the extraction of $\mathrm{Tb}, \mathrm{Dy}$, IIo, Er, Tm and $\mathrm{Yb}$ with 8-hydroxyquinoline in $\mathrm{CICl}_{3}$ from water phase only six-coordinated species of the type $\mathrm{LnOx}_{3}$ were extracted. Oxine did not form self-adducts in these systems. It may be caused by smaller value of IIOx than $5,7(\mathrm{Cl}) \mathrm{HIO}$ distribution constant $[5,9]$.

The influence of MeOII on the nature of the species extracted is shown in Fig. 2 on the example of $\mathrm{Tm}$ (III) extraction. Plots of $\log D-3 \mathrm{pH}^{*}$ vs. $\log \left[\mathrm{HL}_{(\mathrm{o})}\right]$ and $\log D-3 \mathrm{pI}^{*}-3 \log \left[\mathrm{HL}_{(\mathrm{o})}\right]$ vs. $\log \left[\mathrm{MeOII}_{(o)}\right]$ are always linear with slopes $\approx 3$ and $\approx 2$, respectively. These findings would lead to the conclusion that in the presence of methanol in the aqueous phase mixed ligand adducts of the type 

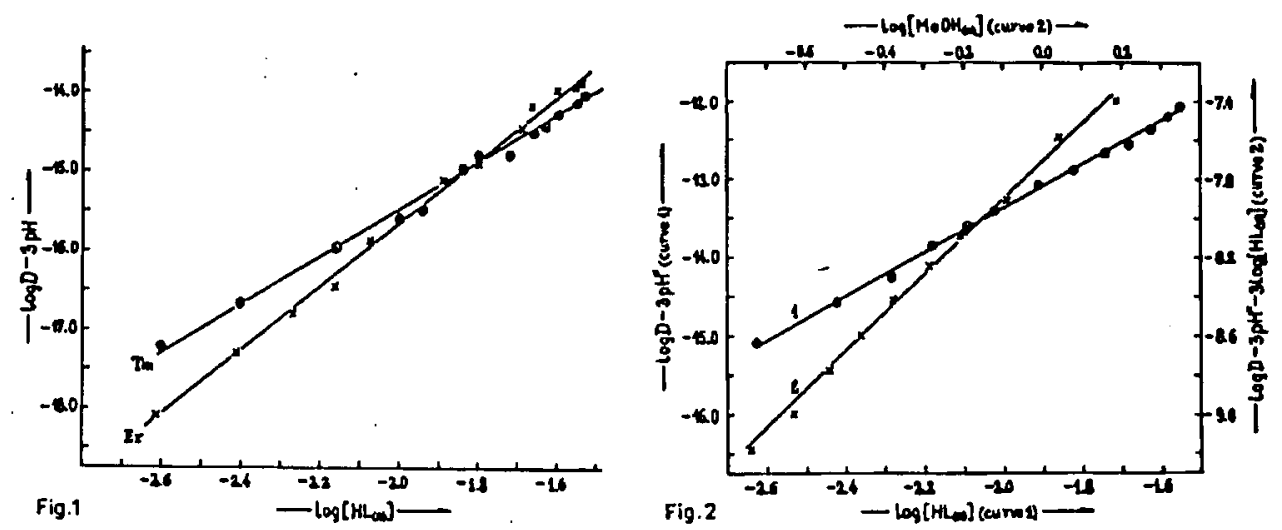

Fig. 1. Extraction of $\operatorname{Er}(\mathrm{III})$ and $\operatorname{Tm}(\mathrm{III})$ with $5,7(\mathrm{Cl}) \mathrm{HO}$ in chloroform from the water pliase. Plots of $\log D-3$ pII vs. $\log \left[\mathrm{IL}_{(0)}\right]$.

Fig. 2. Extraction of $\mathrm{Tm}$ (III) with $5,7(\mathrm{Cl}) \mathrm{IIOx}$ in chloroform from the water-methanol phase. Curves: $1-$ plot of $\log D-3 \mathrm{pH}^{*}$ vs. $\log \left[\mathrm{HL}_{(\mathrm{o})}\right]$ at $C_{\mathrm{MeOH}}=50 \%(\mathrm{~V} / \mathrm{V}) ; 2-$ plot of $\log D-3 \mathrm{pH}^{*}-3 \log \left[\mathrm{HL}_{(\mathrm{o})}\right]$ vs. $\log \left[\mathrm{MeOH}_{(\mathrm{o})}\right]$ at $C_{\mathrm{HL}(\mathrm{o})}=3.00 \times 10^{-2} \mathrm{~mol} / \mathrm{l}$ and $C_{\mathrm{MeOH}}=5 \div 50 \%(\mathrm{~V} / \mathrm{V})$.

TABLE

The species extracted into organic phase with 5,7-dichloro-8-hydroxyquinoline; $C_{\mathrm{HL}(\mathrm{o})}$ from $1.5 \times 10^{-3}$ to $3.00 \times 10^{-2} \mathrm{~mol} / \mathrm{l} ; C_{\mathrm{Ln}}=50 \mu \mathrm{g} / \mathrm{ml} ;$ temperature $=21 \pm 1^{\circ} \mathrm{C}$; $\mu=0.1 \mathrm{~mol} / \mathrm{l}$.

\begin{tabular}{c|c|c}
\hline \hline System & $\mathrm{Ln}(\mathrm{III})$ & Predominant species \\
\hline \multirow{3}{*}{$\operatorname{Ln}(\mathrm{III})-\mathrm{II}_{2} \mathrm{O}-\mathrm{IIL}-\mathrm{CIICl}_{3}$} & $\mathrm{~Tb}, \mathrm{Tm}$ & $\mathrm{LnL}_{3}$ \\
\cline { 2 - 3 } & $\mathrm{Ilo}, \mathrm{Er}$ & $\mathrm{LnL}_{3} \cdot \mathrm{IIL}$ \\
\cline { 2 - 3 } & $\mathrm{Dy}, \mathrm{Yb}$ & $\mathrm{LnL}_{3}$ and $\mathrm{LnL}_{3} \cdot \mathrm{ILL}^{a}$ \\
& $\mathrm{Lu}[2]$ & \\
\hline \multirow{3}{*}{$\mathrm{Ln}(\mathrm{III})-\mathrm{II}_{2} \mathrm{O}-\mathrm{M} \mathrm{IeOII}-\mathrm{IIL}-\mathrm{CHCl}_{3}$} & $\mathrm{~Tb}, \mathrm{Dy}$, & \\
& $\mathrm{IJo}, \mathrm{Er}$, & $\mathrm{LnL}_{3} \cdot 2 \mathrm{MeOII}$ \\
& $\mathrm{Tm}, \mathrm{Tb}$ & \\
\hline
\end{tabular}

${ }^{a}$ In great part at $C_{11 \mathrm{~L}(\mathrm{o})}>1.5 \times 10^{-2} \mathrm{~mol} / \mathrm{l}$.

$\mathrm{LnL}_{3} \cdot 2 \mathrm{MeOII}$ are formed. Similar adducts were also observed in the extraction of heavy lanthanides with IIOx [5]. The formation of eight-coordinated adducts with two molecules of $\mathrm{MeOII}$ is combined with greater lanthanides(III) affinity to $\mathrm{O}$-donor atom than to $\mathrm{N}$-donor atom as well as with steric factor.

A possible structures of the species extracted into the organic phase with 5,7-dichloro-8-hydroxyquinoline are: 

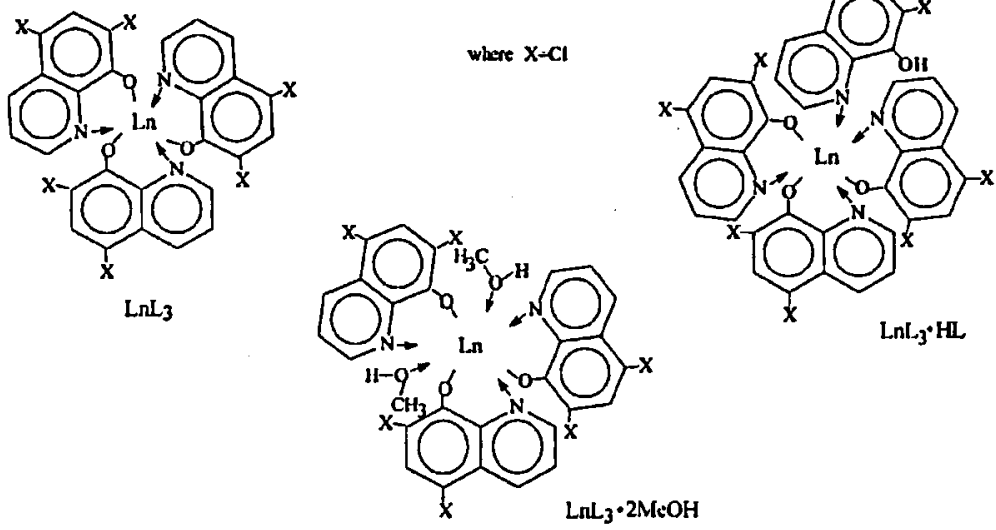

The increase in coordination number from 6 (or 7 ) to 8 for species extracted with $5,7(\mathrm{Cl}) \mathrm{HO}$ as well as with IIOx can explain the synergism observed in the extraction of lanthanides(III) from water-methanol phase.

The study of the extraction parameters in investigated systems will be the matter of our next paper.

\section{References}

[1] J.N. Mathur, Solv. Extr. Ion Exch. 1, 349 (1983).

[2] J. Noro, T. Sekine, Bull. Chem. Soc. Jpn. 66, 2564 (1993).

[3] B. Kużnik, J. Inorg. Nucl. Chem. 43, 3363 (1981).

[4] K. Fujinaga, M. Hojjatie, II. Freiser, Anal. Scien. 4, 139 (1988).

[5] D. Czakis-Sulikowska, B. Kuźnik, A. Malinowska, U. Kijanowicz, Chem. Anal. 38, 53 (1993).

[6] H. Freiser, Solv. Extr. Ion Exch. 6, 1093 (1988).

[7] S. Taguchi, M. Hojjatie, II. Freiser, Anal. Chim. Acta 197, 333 (1987).

[8] R. Bates, Determination of pII. Theory and Practice, Wiley, New York 1964, p. 200.

[9] D. Czakis-Sulikowska, N. Pustelnik, unpublished data.

[10] B. Kuźnik, Monatsh. Chem. 115, 289 (1984).

[11] D. Czakis-Sulikowska, J. Radwańska-Doczekalska, B. Kuźnik, N. Pustelnik, Chem. Anal. 35, 529 (1990). 